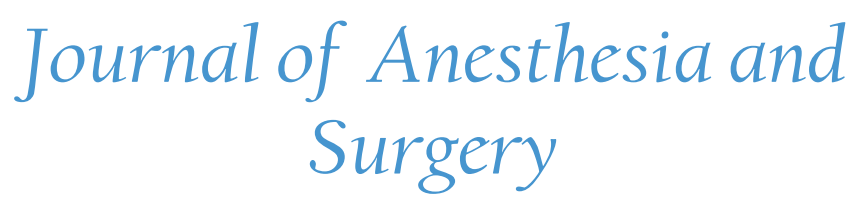

\title{
Does the Choice of Ketamine or Thiopentone as the Induction Agent for Rapid Sequence Induction in Trauma Affect Outcomes? A Retrospective Observational Pilot Study
}

\author{
Ian Ferguson ${ }^{1 *}$, Angus Wilkinson ${ }^{2}$, Anna Holdgate ${ }^{3}$
}

${ }^{1}$ Senior Staff Specialist, Liverpool Hospital, and Conjoint Senior Clinical Lecturer, University of New South Wales, Australia ${ }^{2}$ Intern, New South Wales Health

${ }^{3}$ Senior Staff Specialist, Liverpool Hospital, and Conjoint Associate Professor, University of New South Wales, Australia

*Corresponding author: Ian Ferguson, Emergency Department, Liverpool Hospital, Locked Bag, Liverpool, 1871, Australia, Tel: 0403 859555; E-mail: Ian.Ferguson@sswahs.nsw.gov.au

\begin{abstract}
Objectives: Injured patients requiring intubation usually undergo rapid sequence induction, which has the potential to exacerbate physiologic instability. This study aimed to identify the physiological characteristics and induction agents of trauma patients intubated in our Emergency Department, and investigate whether the choice of ketamine or thiopentone was associated with better outcomes.

Methods: This was a retrospective study of 96 patients identified from the trauma database at a tertiary teaching hospital. Trauma patients intubated in the emergency department with either ketamine or thiopentone were included. We examined the association between the patient's functional status at hospital discharge or 6 months (whichever was sooner), the induction agent, and other recognized prognostic variables such as Glasgow Coma Score, blood pressure and oxygen saturation.

Results: 148 patients were intubated during the study period, 96 of who were eligible for inclusion. 56 were intubated with thiopentone and 40 with ketamine. Fifty percent of patients in each group were eventually discharged from hospital at their baseline level of function. On univariate analysis, survival rates were similar whether induced with ketamine or thiopentone ( $85 \% v s .77 \%, \mathrm{p}=0.33)$, as were rates of independent living at discharge $(75 \%$ vs. $73 \%, \mathrm{p}=0.82)$. Systolic blood pressures were lower in the ketamine group $(\mathrm{p}<0.01)$. Increasing age $(\mathrm{p}<0.01)$, reducing GCS $(\mathrm{p}<0.01)$, and an abnormal cerebral CT scan $(p=0.03)$ were all significantly associated with a poorer outcome.

Conclusion: No difference in outcome was seen whether patients were intubated with ketamine or thiopentone in this small retrospective cohort.
\end{abstract}

Received date: August 27, 2016

Accepted date: October 12, 2016

Published date: October 17, 2016

Citation: Ferguson, I., et al. Does the Choice of Ketamine or Thiopentone as the Induction Agent for Rapid Sequence Induction in Trauma Affect Outcomes? A Retrospective Observational Pilot Study. (2016) J Anesth Surg 3(2): 177-180.

DOI: $10.15436 / 2377-1364.16 .051$

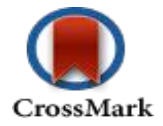

\section{Introduction}

Trauma is a significant cause of morbidity and mortality in Australia, with 87,887 trauma related admissions in $2004 / 5^{[1]}$. Polytrauma frequently involves traumatic brain injury (TBI), which can be divided into primary and secondary processes. Primary injury is immediate and irreversible, caused as a direct result of the force of the trauma ${ }^{[2]}$, whilst secondary injury occurs from minutes to weeks after the initial trauma, as a result of ongoing systemic insults ${ }^{[3]}$. A sub-set of severely injured trauma patients require intubation to maintain a patent airway and allow adequate ventilation in order to limit the extent of secondary brain injury, or to facilitate further care, such as imaging and radiological or surgical intervention. Intubation in these cases usually involves rapid sequence induction (RSI), although the agents used to facilitate intubation may result in hypotension, 
and delays in, or failure of, the procedure can cause hypoxia. Therefore it is important to balance the risks and benefits of the procedure, and to tailor the drug regimen used to minimize the likelihood of adverse events.

Clinical parameters, such as lower Glasgow Coma Scores (GCS), hypotension \&hypoxia are known to affect the outcome of intubated trauma patients ${ }^{[4-10]}$, but there is little data analyzing the effect of choice of induction agent on outcome. More specifically there is no comparison of ketamine and thiopentone as induction agents in the trauma setting.

Until recently, ketamine has been regarded as relatively contra-indicated in head injured patients, on the basis of reports published in the 1970s, demonstrating that it increased intracranial pressure (ICP) ${ }^{[1-13]}$. However, these studies were of poor methodological quality, and increases in ICP were only seen in those with obstructed CSF pathways. The external validity of these studies to trauma is questionable, and later studies of ketamine for sedation of head injured patients in ICU have shown that whilst it may produce minimal increases in ICP, cerebral perfusion pressure is maintained, as mean arterial pressure is also higher ${ }^{[14,15]}$. This maintenance of mean arterial pressure is a theoretical advantage in a population where the potential for hypotension and brain injury co-exist ${ }^{[16,17]}$.

Thiopentone is a potent barbiturate that has been widely used for RSI for decades. However, due to myocardial depression and venodilation ${ }^{[4]}$ it commonly causes a reduction in mean arterial pressure ${ }^{[17-20]}$, and so may theoretically be associated with worse out comes in traumatic brain injury.

Given the risk of thiopentone-induced hypotension, and the questionable nature of the evidence that ketamine is contraindicated in head injured patients, there is a theoretical benefit to using ketamine as an induction agent in trauma patients. Consequently, this pilot study was conducted, with the following aims:

1) To identify and describe the characteristics and outcomes of trauma patients who are intubated in our Emergency Department,

2) To identify the agents used to facilitate intubation, and

3) To investigate which characteristics and induction agents are associated with better outcomes in this cohort?

\section{Methods}

\section{Setting}

This study was performed at the Emergency Department of an 855-bed tertiary care hospital in Sydney, with an annual census of 75,000 presentations per year, including approximately 350 patients with an injury severity score (ISS) of greater than 12. The Human Research Ethics Committee of the South West Sydney Local Health District approved the study, and waived the need for informed consent.

\section{Data sources}

All trauma patients requiring intubation from January 2011 to December 2012 were identified from hospital's Trauma Registry. The following inclusion criteria were used: (1) patients presenting to the Emergency Department following trauma (2) aged 18 years and older, (3) requiring intubation whilst in the ED.

Exclusion criteria were: deceased within 1 hour of ar- rival; intubated prior to arrival in the ED; intubated subsequent to transfer from the ED; patients intubated for burns and/or transferred to another centre.

\section{Variables and outcomes}

The primary outcome was the functional status at hospital discharge, or six months post-injury, whichever was sooner. This was gained from information in the medical record extracted by a single investigator (AW), with cross-checking of a pre-determined selection by a second investigator (IF), as well as adjudication by the second investigator in all cases of doubt. Patients were classified into the categories shown in (Table 1).

Table 1: Functional status at discharge or six months.

\begin{tabular}{|l|l|}
\hline Group 1 & Dead \\
\hline Group 2 & Functionally dependent \\
\hline Group 3 & Able to live independently, but not at baseline level \\
\hline Group 4 & Return to baseline level of function \\
\hline
\end{tabular}

The following data variables were collected: patient age and sex, mechanism of injury (blunt or penetrating), GCS on presentation to the ED, lowest GCS before induction, blood pressure on presentation, lowest blood pressure in ED, lowest oxygen saturation in ED, induction agent and CT brain findings (dichotomised into formally reported as normal or abnormal).

\section{Data analysis and sample size estimate}

All data were analyzed using Stata version 11 (Statacorp, TX, USA). As there was no data on which to base a power calculation, we used the logistic regression 'rule of thumb' aiming for 10 patients for each independent variable, giving a sample size of 10020 . Univariate analysis was conducted using the Chi squared test for proportions and independent t-tests for normally distributed continuous data and Mann-Whitney u-test for non-normal continuous data. Logistic regression analysis was then conducted using a dichotomised composite of the primary outcome as the outcome variable (groups $1 \& 2-$ dead or dependent, versus groups $3 \& 4$ - living independently). Variables with $\mathrm{P}<0.25$ on univariate analysis were included in the baseline multivariate logistic regression model.

\section{Results}

A total of 148 trauma patients were identified as being intubated over the 24-month study period. Thirty-two of these were excluded: 4 patients were intubated outside the ED, 25 were intubated for burns and two for toxidromes, rather than trauma. One patient died within one an hour of presentation. Two patients were given both ketamine and thiopentone prior to intubation and were also excluded. Of the remaining 116 patients, 56 were intubated using thiopentone, 40 with ketamine, 16 with propofol and 4 without any induction agent. In keeping with the aims of the study, only the patients who received ketamine or thiopentone were included in the analysis. Demographic data and clinical parameters are outlined in (Table 2). Patients in the ketamine group had significantly lower systolic blood pressure compared with patients who received thiopentone (initial SBP 119 vs. $137 \mathrm{mmHg}$ p < 0.01; lowest ED SBP 88 vs. $107 \mathrm{mmHg}$ $1, \mathrm{p}<0.01$ ) but otherwise had similar characteristics. 
Table 2: Characteristics of patients in the ketamine and thiopentone groups.

\begin{tabular}{|l|l|l|l|}
\hline & $\begin{array}{l}\text { Ketamine } \\
\text { Group } \\
(\mathbf{n}=\mathbf{4 0})\end{array}$ & $\begin{array}{l}\text { Thiopentone } \\
\text { Group } \\
\text { (n= 56) }\end{array}$ & p-value \\
\hline Male Sex (\%) & $70 \%$ & $80 \%$ & 0.26 \\
\hline Age (median; IQR) & $40(24-59)$ & $44.5(29-67)$ & 0.38 \\
\hline Mechanism: Blunt & $83 \%$ & $91 \%$ & 0.24 \\
\hline $\begin{array}{l}\text { Admission GCS } \\
\text { (median; IQR) }\end{array}$ & $10(8-14)$ & $9.5(5.5-13)$ & 0.35 \\
\hline $\begin{array}{l}\text { Lowest GCS (median; } \\
\text { IQR) }\end{array}$ & $10(7.5-13)$ & $8(4.5-13)$ & 0.12 \\
\hline $\begin{array}{l}\text { Admission systolic blood } \\
\text { pressure, mmHg } \\
\text { (median; IQR) }\end{array}$ & $119(106-40)$ & $137(119-171)$ & $<0.01$ \\
\hline $\begin{array}{l}\text { Lowest systolic blood } \\
\text { pressure, mmHg } \\
\text { (median; IQR) }\end{array}$ & $88(70-114)$ & $107(94-133)$ & $<0.01$ \\
\hline $\begin{array}{l}\text { Lowest O saturation } \\
\text { (median; IQR) }\end{array}$ & $98(90-100)$ & $98(95-100)$ & 0.45 \\
\hline Abnormal CT scan & $38 \%$ & $46 \%$ & 0.43 \\
\hline
\end{tabular}

In the unadjusted analysis, mortality was similar in the ketamine and the thiopentone groups $(15 \%$ versus $23 \%, \mathrm{p}=$ 0.33 ) and approximately $50 \%$ of patients in each group returned to baseline function at discharge(Table 3 ). In the logistic regression after allowing for all other variables, there was no difference in functional outcomes between the two induction agents, with an odds ratio for a poor functional outcome (dead or moderate to severe disability) if induced with ketamine of $0.51(95 \%$ CI 0.14 - 1.93).

Table 3: Patient functional status by induction agent (unadjusted).

\begin{tabular}{|l|c|c|}
\hline & Ketamine & Thiopentone \\
\hline Dead & $15 \%$ & $23 \%$ \\
\hline Functionally dependent & $10 \%$ & $4 \%$ \\
\hline $\begin{array}{l}\text { Able to live independently, but not } \\
\text { at baseline level }\end{array}$ & $27 \%$ & $21 \%$ \\
\hline Return to baseline level of function & $48 \%$ & $52 \%$ \\
\hline
\end{tabular}

Factors that were associated with poorer functional outcomes in the logistic regression were increasing age, lower GCS, and an abnormal cerebral CT scan. The odds ratio for a poor functional outcome was 1.05 per year increase in age $(95 \%$ CI 1.02 - 1.09). For every one point increase in the lowest GCS, the odds ratio of a poor outcome was 0.72 (95\% CI $0.59-0.88)$, and the odds ratio for a poor outcome with an abnormal CT was 3.99 (95\% CI 1.12 - 14.14) (Table 4).

Table 4: Logistic regression using poor functional outcome (died or dependent).

\begin{tabular}{|l|l|l|l|}
\hline & \multicolumn{3}{|l|}{ Group 3\&4 } \\
\hline & $\begin{array}{l}\text { Odds } \\
\text { Ratio }\end{array}$ & $\begin{array}{l}\text { 95\% confidence } \\
\text { interval }\end{array}$ & p value \\
\hline Age (increase in one yr) & 1.05 & $1.02-1.09$ & $\leq 0.01$ \\
\hline $\begin{array}{l}\text { Lowest GCS (increase } \\
\text { in one point) }\end{array}$ & 0.72 & $0.59-0.88$ & $\leq 0.01$ \\
\hline Abnormal CT & 3.99 & $1.12-14.14$ & 0.03 \\
\hline
\end{tabular}

\section{Limitations}

Our study was a retrospective cohort, and so is subject to possible bias. The use of the case files to determine outcomes is less reliable than clinical review or telephone follow up, but we used broad end-points, which we would argue are relevant to patients, and feel that this was acceptable.

\section{Discussion}

The patients intubated following trauma in our centre were a critically ill cohort, with only $50 \%$ of them returned to the baseline function by six months post injury. The majority of patients were young men, suffering from blunt trauma, typical of the demographics seen in Australasian trauma centers. Given this demographic, the societal burden of incomplete recovery is high, and any improvement in outcomes is likely to have significant economic, as well as clinical benefit.

Our study shows that thiopentone remained the most frequently used induction agent in trauma at our centre, with ketamine being the second most popular agent. We found that the main difference between patients induced with thiopentone and ketamine was that those who received ketamine had significantly lower blood pressure in the ED. This most likely represents clinician choice guided by the patient's physiological status, with ketamine used more frequently in patients who are haemodynamically unstable. Both the unadjusted analysis and the logistic regression showed a no difference in discharge outcome based on the induction agent.

Our data confirms the association of a lower GCS, increasing age, and an abnormal CT scan with poorer outcomes in trauma patients, but we did not show poorer outcomes associated with hypoxia or hypotension. The former may reflect the relatively low prevalence of hypoxia in our study. It is possible that both hyper- and hypotension are associated with poorer outcomes, as some patients with severe isolated head injuries may exhibit a Cushing response, which may explain the lack of association between low BP and poor outcome in our study.

The major limitation of our study was the use of a retrospective cohort methodology. Because the choice of induction agent appeared influenced by baseline blood pressure, we were unable to determine the independent influence of the induction agents on our outcome of interest. However, our data does provide important information to better inform researchers in planning a randomized trial to further investigate this issue.

\section{Conclusion}

This small, retrospective pilot study shows that trauma patients intubated in the ED are a critically ill cohort, and that thiopentone and ketamine are the most frequently used induction agents for this group. However, there was no evidence that the use of either ketamine or thiopentone had any independent influence on patient outcome, and consequently at present the choice of agent should continue to be guided by the experience of treating clinicians. Prospective study, ideally a randomized controlled trial, is needed to definitively answer the question of whether the choice of induction agent influences outcome in the trauma patient requiring intubation.

Conflicts of Interest: Authors declare no conflicts of interest. 


\section{References}

1. NSW Department of Health. NSW Trauma Services: Selected Specialty and Statewide Service Plans: Number Six. (2009) NSW Department of Health retrieved $17^{\text {th }}$ March 2013.

2. Tintinalli, J.E., Stapczynski, J.S., Ma, O.J., et al. Tintinalli's Emergency Medicine: A Comprehensive Study Guide ( $7^{\text {th }}$ ed). (2011) Sydney: McGraw-Hill Companies

3. Marx, J.A., Hockberger, R.S., Walls, R.M. Rosen's Emergency Medicine: Concepts and Clinical Practice ( $7^{\text {th }}$ edition). (2010) Philadelphia: Mosby Elsevier

4. Lenartova, L., Janciak, I., Wilbacher, I., et al. Severe traumatic brain injury in austria III: prehospital status and treatment. (2007) Wien Klin Wochenschr 119(1-2): 35-45.

5. McHugh, G.S., Engel, D.C., Butcher, I., et al. Prognostic value of secondary insults in traumatic brain injury: results from the IMPACT study. (2007) J Neurotrauma 24(2): 287-293.

6. Zenati, M.S., Billiar, T.R., Townsend, R.N., et al. A brief episode of hypotension increases mortality in critically ill trauma patients. (2002) J Trauma 53(2): 232-237.

7. Berry, C., Ley, E.J., Bukur, M., et al. Redefining hypotension in traumatic brain injury. (2012) Injury 43(11): 1833-1837.

8. Brenner, M., Stein, D.M., Hu, P.F., et al. Traditional systolic blood pressure targets underestimate hypotension-induced secondary brain injury. (2012) J Trauma Acute Care Surg 72(5): 1135-1139.

9. Edelman, D.A., White, M.T., Tyburski, J.G., et al. Post-traumatic hypotension: should systolic blood pressure of $90-109 \mathrm{mmhg}$ be included? (2007) Shock 27(2): 134-138.

10. Chi, J.H., Knudson, M.M., Vassar, M.J., et al. Prehospital hypoxia affects outcome in patients with traumatic brain injury: a prospective multicentre study. (2006) J Trauma 61(5): 1134-1141.
11. Shapiro, H.M., Wyte, S.R., Harris, A.B. Ketamine anaesthesia in patients with intracranial pathology. (1972) Br J Anaesth 44(11): 12001204.

12. Gardner, A.E., Dannemiller, F.J., Dean, D. Intracranial cerebrospinal fluid pressure in man during ketamine anesthesia. (1972) Anesth Analg 55(5): 741-745.

13. Wyte, S.R., Shapiro, H.M., Turner, P. Ketamine-induced intracranial hypertension. (1972) Anesthesiology 36(2): 174-176.

14. Kolenda, H., Gremmelt, A., Rading, S., et al. Ketamine for analgosedative therapy in intensive care treatment of head-injured patients. (1996) Acta Neurochir (Wien) 138(10): 1193-1199.

15. Bourgoin, A., Albanese, J., Wereszcynski, N., et al. Safety of sedation with ketamine in severe head injury patients: comparison with sufentanil. (2003) Crit Care Med 31(3): 711-717.

16. Sih, K., Campbell, S.G., Tallon, J.M., et al. Ketamine in adult emergency medicine: controversies and recent advances. (2011) Ann Pharmacother 45(12): 1525-1534.

17. Urwin, S.C., Menon, D.K. Comparative tolerability of sedative agents in head-injured adults. (2004) Drug Saf 27(2): 107-133.

18. Sivilotti, M.L., Ducharme, J. Randomized, double-blind study on sedatives and hemodynamics during rapid-sequence intubation in the emergency department: the SHRED study. (1998) Ann Emerg Med 31(3): $\neg-313-324$.

19. Roberts, I., Sydenham, E. Barbiturates for acute traumatic brain injury. (2012) Cochrane Database Syst Rev 12: CD000033.

20. Peduzzi, P., Concato, J., Kemper, E., et al. A simulation study of the number of events per variable in logistic regression analysis. (1996) $\mathrm{J}$ Clin Epidemiol 49(12): 1373-1379.
Ommega Online Publishers

Journal Title: Journal of Anesthesia and Surgery (JAS)

Journal Short Name: J Anesth Surg
Journal ISSN: 2377-1364

E-mail: anestheisa@ommegaonline.com

Website: www.ommegaonline.org 